\section{Fetal hemoglobin induction during decitabine treatment of elderly patients with high-risk myelodysplastic syndrome or acute myeloid leukemia: a potential dynamic biomarker of outcome}

\author{
Julia Stomper, ${ }^{1}$ Gabriele Ihorst, ${ }^{2}$ Stefan Suciu, ${ }^{3}$ Philipp N. Sander, ${ }^{1,4}$ Heiko \\ Becker, ${ }^{1}$ Pierre W. Wijermans, ${ }^{5}$ Christoph Plass, ${ }^{6,7}$ Dieter Weichenhan, ${ }^{6}$ \\ Emmanuel Bissé, ${ }^{8}$ Rainer Claus ${ }^{1,9}$ and Michael Lübbert ${ }^{1,10}$
}

${ }^{1}$ Department of Hematology, Oncology, and Stem Cell Transplantation, Faculty of Medicine and Medical Center, University of Freiburg, Germany; ${ }^{2}$ Clinical Trials Unit, Faculty of Medicine and Medical Center, University of Freiburg, Germany; ${ }^{3}$ EORTC Headquarters,

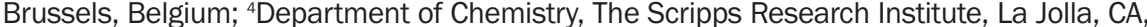
USA; ${ }^{5}$ Department of Hematology, Haga Hospital, The Hague, the Netherlands; ${ }^{6}$ DKFZ Heidelberg, Division of Epigenomics and Cancer Risk Factors, Heidelberg, Germany; ${ }^{7}$ German Cancer Research Consortium (DKTK), Heidelberg, Germany; ${ }^{8}$ Institute for Clinical Chemistry and Laboratory Medicine, Faculty of Medicine and Medical Center, University of Freiburg, Germany; ' Department of Internal Medicine II, Hematology/Oncology, Augsburg Medical Center, Germany and ${ }^{10}$ German Cancer Research Consortium (DKTK), Freiburg, Germany

\section{ABSTRACT}

H ematologic responses to hypomethylating agents are often delayed in patients with myelodysplastic syndrome or acute myeloid leukemia. Fetal hemoglobin is a potential novel biomarker of response: recently, we demonstrated that a high fetal hemoglobin level prior to decitabine treatment was associated with superior outcome. Here we investigated whether early fetal hemoglobin induction during decitabine treatment also had prognostic value, and studied the potential of decitabine to induce erythroid differentiation and fetal hemoglobin expression in vitro. Fetal hemoglobin levels were measured by high-performance liquid chromatography in patients with higher-risk myelodysplastic syndrome $(n=16)$ and acute myeloid leukemia $(n=37)$ before treatment and after each course of decitabine. Levels above $1.0 \%$ were considered induced. Patients achieving complete or partial remission as best response had attained a median fetal hemoglobin of $1.9 \%$ after two courses of treatment, whereas the median value in patients who did not reach complete or partial remission was $0.8 \%(P=0.015)$. Fetal hemoglobin induction after two courses of decitabine treatment was associated with early platelet doubling $(P=0.006)$, and its subsequent decrease with hematologic relapse. In patients with myelodysplastic syndrome, induction of fetal hemoglobin after course 2 of treatment was associated with longer overall survival: median of 22.9 versus 7.3 months in patients with or without induction of fetal hemoglobin, respectively [hazard ratio $=0.2$ (95\% confidence interval: $0.1-0.9) ; P=0.03$ ]. In vitro decitabine treatment of two bi-potential myeloid leukemia cell lines (K562 and HEL) resulted in induction of an erythroid (not megakaryocytic) differentiation program, and of fetal hemoglobin mRNA and protein, associated with GATA1 gene demethylation and upregulation. In conclusion, fetal hemoglobin may provide a useful dynamic biomarker during hypomethylating agent therapy in patients with myelodysplastic syndrome or acute myeloid leukemia.
Ferrata Storti Foundation

Haematologica 2019

Volume 104(1):59-69

\section{Correspondence:}

michael.luebber@@uniklinik-freiburg.de

Received: December 30, 2017.

Accepted: August 28, 2018.

Pre-published: August 31, 2018.

doi:10.3324/haematol.2017.187278

Check the online version for the most updated information on this article, online supplements, and information on authorship \& disclosures: www.haematologica.org/content/104/1/59

\section{(C)2019 Ferrata Storti Foundation}

Material published in Haematologica is covered by copyright. All rights are reserved to the Ferrata Storti Foundation. Use of published material is allowed under the following terms and conditions:

https://creativecommons.org/licenses/by-nc/4.0/legalcode. Copies of published material are allowed for personal or internal use. Sharing published material for non-commercial purposes is subject to the following conditions:

https://creativecommons.org/licenses/by-nc/4.0/legalcode, sect. 3. Reproducing and sharing published material for commercial purposes is not allowed without permission in writing from the publisher. 


\section{Introduction}

DNA-hypomethylating agents (HMAs) alter gene expression of malignant cells by gene reactivation, e.g. of epigenetically silenced tumor suppressor genes resulting in induction of apoptosis or senescence, ${ }^{1.4}$ or of cancer/testis antigens and retroviral sequences, thus eliciting an immune response against cancer cells, 5,6 and by reduction of oncogene overexpression. ${ }^{7}$ In cell line models of acute myeloid leukemia (AML), they also induce granulocytic maturation although this effect has yet to be validated in vivo. ${ }^{8}$

Probably the earliest proof of therapeutic gene reactivation by an HMA was the demonstration of induction of fetal hemoglobin $(\mathrm{HbF})$ in a patient with severe beta-thalassemia through demethylation and transcriptional activation of the gamma-globin gene locus, " the developmental regulation of which is governed by DNA methylation. This ability of HMAs to de-repress epigenetically silenced gamma-globin expression in (polyclonal) erythropoietic precursors has also been observed in patients with solid tumors ${ }^{10,11}$ and has prompted clinical trials on the use of HMAs in hemoglobinopathies. ${ }^{12,13}$

Several groups have shown that in patients with myelodysplastic syndrome (MDS) or AML receiving azacitidine, $\mathrm{HbF}$ is induced and may be a marker of treatment effect. ${ }^{14,15}$ Very recently, we observed elevated $\mathrm{HbF}$ levels also in MDS/AML patients treated with decitabine ${ }^{16} \mathrm{We}$ now dissected the kinetics of the in vivo induction of $\mathrm{HbF}$ in these patients with high-risk MDS or AML, in order to evaluate the prognostic value of $\mathrm{HbF}$ induction. We observed that $\mathrm{HbF}$ levels after two courses of treatment were of prognostic value regarding hematologic responses of the different lineages, and, in MDS, for overall survival from this time point on [hazard ratio (HR) $=0.2 ; 95 \%$ confidence interval $(95 \% \mathrm{CI}): 0.1-0.9 ; P=0.03]$. The cellular source of $\mathrm{HbF}$ in responders appeared to be predominantly non-malignant erythroid precursors. To model $\mathrm{HbF}$ reactivation in vitro, we investigated two transformed leukemia cell lines for the induction of an erythroid differentiation program that also encompassed $\mathrm{HbF}$ protein synthesis induced by decitabine.

\section{Methods}

\section{Patients, treatments and response evaluations}

Details on the patients, the treatments given and evaluation of responses are provided in the Online Supplement. Both the therapeutic studies and the translational investigations were approved by the institutional review board (ethics committee) of the University of Freiburg Medical Center. Patients (all treated at the Freiburg study site) provided their written informed consent to be included in the respective clinical studies, and to related translational investigations according to the Declaration of Helsinki.

\section{Hemoglobin quantification by high-performance liquid chromatography}

HbF levels were measured by high-performance liquid chromatography (HPLC) before treatment and after the end of each treatment course (every 6 weeks) as described previously. ${ }^{17}$ Patients were grouped by normal ( $\mathrm{HbF} \leq 1 \%$ ) or elevated $\mathrm{HbF}$ levels $(\mathrm{HbF}>1 \%)$, in accordance with reference values for the University of Freiburg Medical Center Central Laboratory.

\section{Statistical methods}

We used non-parametric Spearman correlation coefficients $\left(r_{s}\right)$ to assess the association between $\mathrm{HbF}$ levels and other variables. To address the hypothesis that $\mathrm{HbF}$ after course 2 of decitabine treatment may predict hematologic responses after course 4 , we employed linear regression models with $\mathrm{HbF}$ levels as the independent variable, and platelet count, hemoglobin concentration, neutrophil counts, and bone marrow blasts as dependent variables. Results are displayed graphically. The evaluation of possible outliers was based on studentized residuals. ${ }^{18}$ No potential outliers were excluded from the statistical analyses. The $\mathrm{HbF}$ value distributions between responders and non-responders were compared using the Wilcoxon two-sample test. Before-after differences in binary variables such as elevated $\mathrm{HbF}$ (yes/no) were assessed statically using the McNemar test.

Time-to-event endpoints comprised overall survival, progression-free survival, and AML-free survival. We performed landmark analyses starting at the time of $\mathrm{HbF}$ measurements after two cycles of decitabine treatment in order to avoid the so-called immortal-time bias. ${ }^{19}$ Thus, they were relevant only for patients who reached this time point. The Kaplan-Meier method was used to estimate distributions of overall, progression-free and AML-free survival according to $\mathrm{HbF}$ value (> versus $\leq 1 \%$ ), and to compute median estimations. A log-rank test was used to assess the prognostic importance of $\mathrm{HbF}$ value, and a Cox model to estimate the hazard ratio (HR) and its 95\% confidence interval (95\% CI).

Statistical analyses (all conducted at the CTU Freiburg, Germany) were performed with SAS 9.2 (SAS Institute Inc., Cary, NC, USA), and IBM SPSS Statistics 22.

\section{Cell lines and in vitro treatment}

K562 and HEL cells (DMSZ, Braunschweig, Germany) were cultured in RPMI1640 containing 10\% heat-inactivated fetal calf serum. Cells were treated with three 24 -h pulses of 100 and $20 \mathrm{nM}$ decitabine (Sigma Aldrich) and harvested $144 \mathrm{~h}$ after the first treatment, as described previously. ${ }^{20} \mathrm{Hemin}$ (Sigma Aldrich), a positive control for induction of erythroid differentiation, ${ }^{21}$ was added to the culture medium at a final concentration of $50 \mu \mathrm{M} .{ }^{22}$ Cell viability was tested by $0.4 \%$ trypan blue staining. Megakaryocytic differentiation was induced by exposure to $5 \mathrm{nM}$ phorbol ester (PMA, Sigma Aldrich) for $48 \mathrm{~h}$, as described previously. ${ }^{23}$.

Further information on the methods, including transcriptome profiling, immunoblotting, and methyl-CpG immunoprecipitation sequencing, is provided in the Online Supplement.

\section{Results}

\section{Kinetics of in vivo induction of $\mathrm{HbF}$ in patients with myelodysplastic syndrome/acute myeloid leukemia receiving decitabine}

In 40 patients ( 15 with higher-risk MDS, 25 with AML), $\mathrm{HbF}$ was measured serially twice or more during treatment (in a single patient, $\mathrm{HbF}$ before treatment was not available). The patients' characteristics and those of their diseases are presented in Table 1.

When analyzing $\mathrm{HbF}$ kinetics over time (Figure 1A, Online Supplementary Figure S1), the first on-treatment time point with robust $\mathrm{HbF}$ induction was at the end of the second course of decitabine treatment. Compared to the median pre-treatment $\mathrm{HbF}$ of $0.8 \%$, we observed overall induction to $1.1 \%$ after course 2 . The median fold-change of $\mathrm{HbF}$ concentration at the end of the second course of decitabine treatment as compared to pre-treatment levels was $1.67(P=0.088)$. 
By grouping patients according to pre-treatment $\mathrm{HbF}$ levels (normal versus elevated) and subsequent $\mathrm{HbF}$ levels (normal versus increased), four different patterns could be discerned. In patients with normal pre-treatment $\mathrm{HbF}$, $\mathrm{HbF}$ was either induced to levels above the upper limit of normal (group $\mathrm{A}, \mathrm{n}=11$ ) or remained within the normal range (group $B, n=12$ ); among patients with elevated pretreatment levels, $\mathrm{HbF}$ either remained elevated also in subsequent measurements (group $\mathrm{C}, \mathrm{n}=13$, in most cases after an initial drop following the first treatment course) or dropped to normal levels, without subsequent elevation above the upper limit of normal (group D, $n=3$ ). Two vignettes representative of each of the four different patterns of $\mathrm{HbF}$ kinetics are shown in Figure $1 \mathrm{~B}$. The number of treatment courses varied between these four groups: median numbers were $5,2,7$ and 3 courses in groups $A, B$, $C$ and $D$, respectively (range: $2-11,2-6,2-23$, and 2-6 courses, respectively). Consequently, more patients in groups $\mathrm{A}$ and $\mathrm{C}$ attained hematologic responses over time, including complete remission (with suppression of the abnormal clone in patients with initial cytogenetic abnormalities), compared to patients in groups $\mathrm{B}$ and $\mathrm{D}$. $\mathrm{HbF}$ levels were elevated in significantly more patients during treatment (groups $\mathrm{A}+\mathrm{C}: \mathrm{n}=24,61.5 \%$ ) than prior to treatment (groups $\mathrm{C}+\mathrm{D}: \mathrm{n}=16,41.0 \% ; P=0.033$ ).

Early $\mathrm{HbF}$ induction by decitabine has predictive value for subsequent hematologic stabilization and response

Among patients achieving complete or partial remission as their best overall response, a median $\mathrm{HbF}$ of $1.9 \%$ (1.9\% in MDS, $2.0 \%$ in AML) was observed at this time point compared to a median of $0.8 \%(1.0 \%$ and $0.6 \%$, respectively) in patients not attaining complete or partial remission ( $P=0.015)$ (Figure 1C, Online Supplementary Figure S2).

Given that robust $\mathrm{HbF}$ induction during decitabine treatment was first observed after two cycles of treatment, we chose this time point for further analyses regarding the potential value of $\mathrm{HbF}$ induction for predicting subsequent responses. Using linear regression models and correlation analyses, we assessed the association between $\mathrm{HbF}$ levels after course 2 of decitabine treatment and responses in the different hematopoietic lineages after course 4 in all 40 MDS/AML patients ( 3 patients did not receive more than 2 courses, but had peripheral blood counts available 3 months after course 2: one underwent hematopoietic stem cell transplantation, one changed to a different study after course 2 , and one received thalidomide and best supportive care at that point).

Higher HbF levels after two courses were associated with significantly higher platelet counts after four courses $\left(\mathrm{r}_{\mathrm{s}}=0.49, P=0.01\right)$ (Figure 2A). As for neutrophil counts, a trend towards higher counts after course 4 in patients with elevated $\mathrm{HbF}$ levels after course 2 was noted $\left(r_{s}=0.35\right.$, $P=0.08$ ) (Figure $2 B$ ). A borderline significant association was also observed between $\mathrm{HbF}$ levels after two courses of treatment and hemoglobin levels after four courses $\left(r_{s}=0.36\right.$, $P=0.08$ ) (Figure 2C). Interrogating the potential prognostic value of $\mathrm{HbF}$ induction for bone marrow blast suppression after four courses in the entire cohort of $21 \mathrm{MDS} / \mathrm{AML}$ patients with available blast counts, an association was noted $\left(r_{s}=-0.48, P=0.03\right)$ (Figure $\left.2 \mathrm{D}\right)$. When looking at $\mathrm{MDS}$ and AML patients separately, the overall results were similar in both cohorts, particularly for blast suppression (Online Supplementary Figure S4A-D). Moreover, similar results were observed when restricting the same kind of analysis to MDS and AML patients who had received more than four courses of decitabine (data not shown).

In patients achieving platelet doubling already after one course of decitabine, the median $\mathrm{HbF}$ after course 2 was $1.9 \%$, versus $0.8 \%$ in patients without this platelet response $(P=0.006)$ (Figure $2 \mathrm{E})$. In contrast, no correlation was observed between $\mathrm{HbF}$ levels and platelet counts before treatment initiation: $r_{s}=-0.13(P=0.63)$ in $M D S$ $(n=16)$ and $r_{s}=0.02(P=0.91)$ in AML patients $(n=36)$.

\section{Association of HbF induction by decitabine and survival outcomes in patients with myelodysplastic syndrome/acute myeloid leukemia}

Overall, progression-free and AML-free survival were measured from the time of $\mathrm{HbF}$ determination after completion of two courses of decitabine treatment. In the MDS cohort, overall survival was significantly longer in the nine patients in whom $\mathrm{HbF}$ was elevated above the upper limit of normal at that time point than in the six patients with $\mathrm{HbF}$ in the normal range: median 22.9 versus 7.3 months, respectively ( $\mathrm{HR}=0.21$; 95\% CI: 0.05-0.87; $P=0.03$ ) (Figure $3 \mathrm{~A})$. Censoring the six patients who had

Table 1. Characteristics of MDS and AML patients and their disease at baseline.

$\begin{array}{lcc} & \text { MDS } & \text { AML } \\ \text { Age (years; median and range) } & 74(66-77) & 73(62-82) \\ \text { Sex } & 8 & 15 \\ \text { Male } & 7 & 10 \\ \text { Female } & & \end{array}$

FAB subtype

$\begin{array}{cc}\text { RA: } 1 & \text { M1: } 4 \\ \text { RAEB: } 8 & \text { M2: } 2 \\ \text { RAEB-t: } 4 & \text { M4: } 5 \\ \text { CMMoL: } 2 & \text { M5: } 1 \\ & \text { M6: } 3 \\ & \text { N/A: } 10\end{array}$

\begin{tabular}{|c|c|c|}
\hline WBC (x 10\% $/$; median and range) & $2.4(0.8-18.8)$ & $2.2(0.5-27.1)$ \\
\hline ANC (x 109/L; median and range) & $0.93(0.16-2.40)$ & $0.33(0-14.09)$ \\
\hline $\begin{array}{l}\text { Peripheral blood blasts } \\
\text { (\%; median and range) }\end{array}$ & $1(0-13)$ & $19(0-96)$ \\
\hline $\begin{array}{l}\text { Bone marrow blasts } \\
\text { (\%; median and range) }\end{array}$ & $18(2-30)$ & $55(10-95)$ \\
\hline $\mathrm{Hb}$ (g/dL; median and range) & $8.4(5.0-11.3)$ & $8.7(5.6-12.4)$ \\
\hline PLT (x 10%; median and range) & $35(10-151)$ & $34(7-229)$ \\
\hline sLDH (U/; median and range) & $235(102-842)$ & $271(134-1276)$ \\
\hline
\end{tabular}
Cytogenetics

$\begin{array}{cc}\text { Normal: } 3 & \text { Intermediate risk: } 7 \\ \text { Sole } 5 q-: 1 & \text { Poor risk: } 6 \\ \text { Sole }-7: 1 & <10 \text { normal } \\ & \text { metaphases: } 4 \\ \text { Complex: } 6 & \text { No metaphases: } 1 \\ \text { No metaphases: } 4 & \text { N/A: } 7\end{array}$

MDS: myelodysplastic syndrome; AML: acute myeloid leukemia. RA, refractory anemia; RAEB: refractory anemia with blast excess; RAEB-t: refractory anemia with blast excess in transformation (i.e. AML according to the World Health Organization classification); CMMoL: chronic myelomonocytic leukemia.FAB (French-American-British) subtypes: M1: acute myeloblastic leukemia with minimal maturation; M2: acute myeloblastic leukemia with maturation; M4: acute myelomonocytic leukemia; M5: acute monocytic leukemia; M6: acute erythroid leukemia. N/A: not assessed; WBC: white blood cells; ANC: absolute neutrophil counts; Hb: hemoglobin; PLT: platelets; sLDH: serum lactate dehydrogenase. 
A

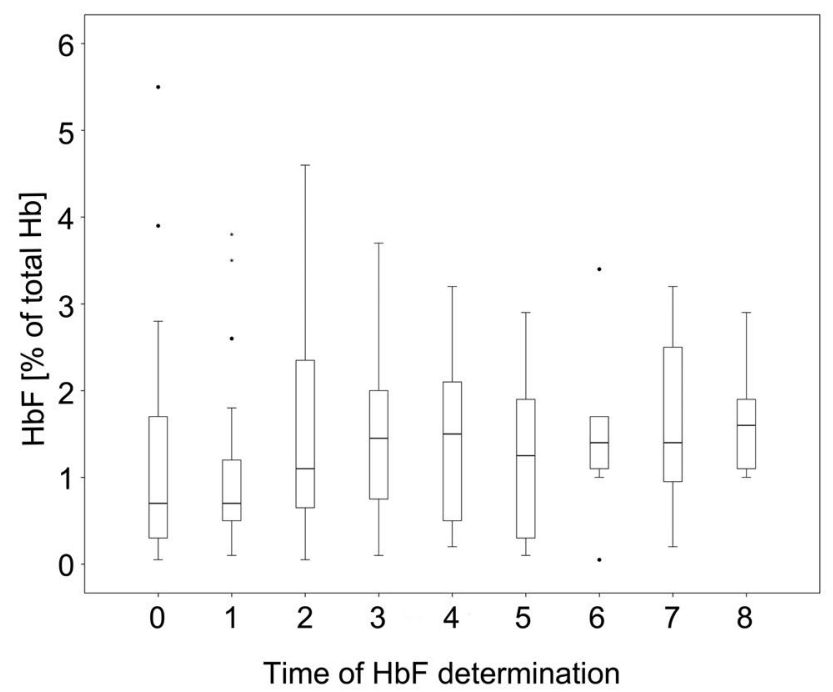

B

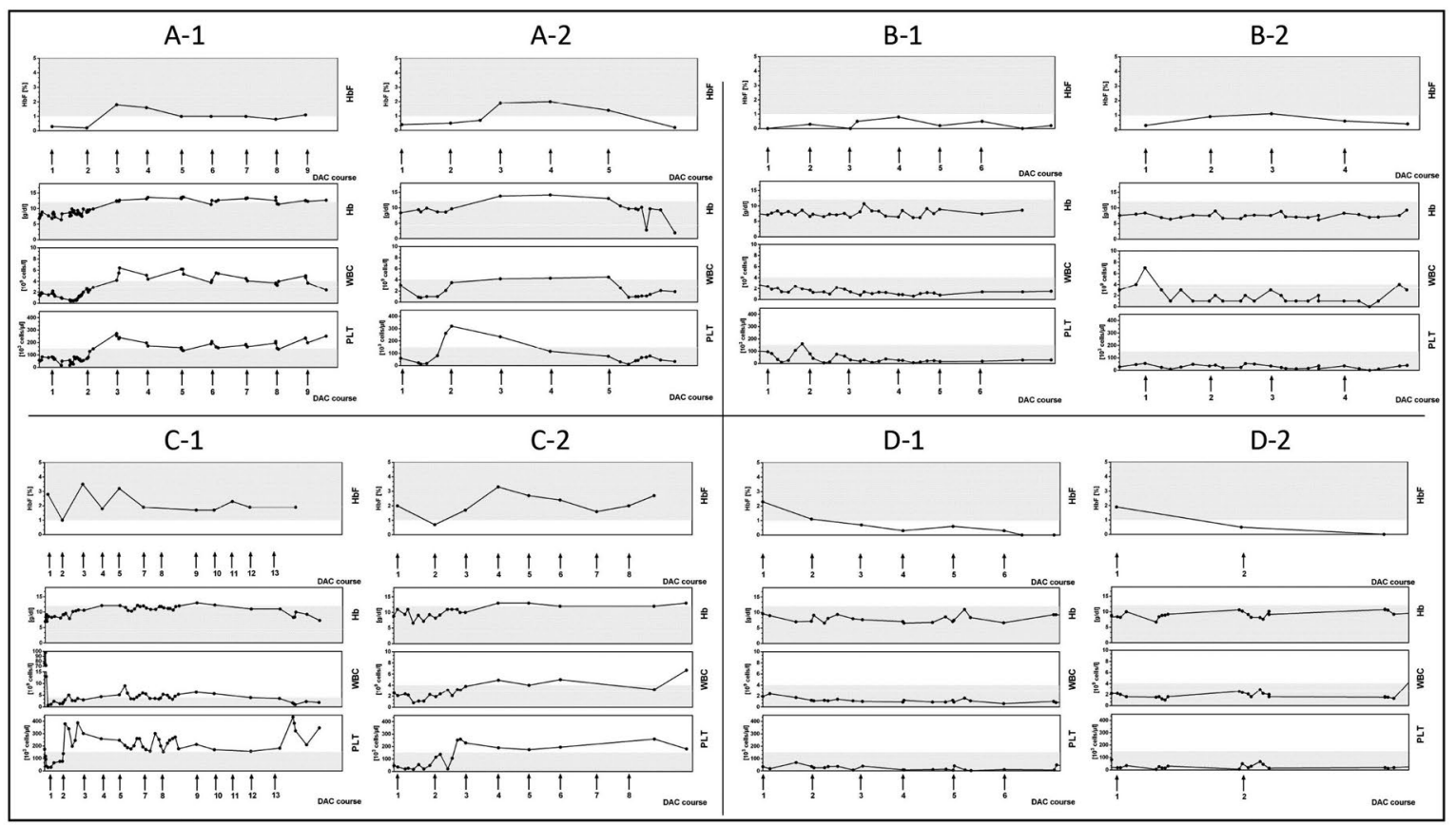

C

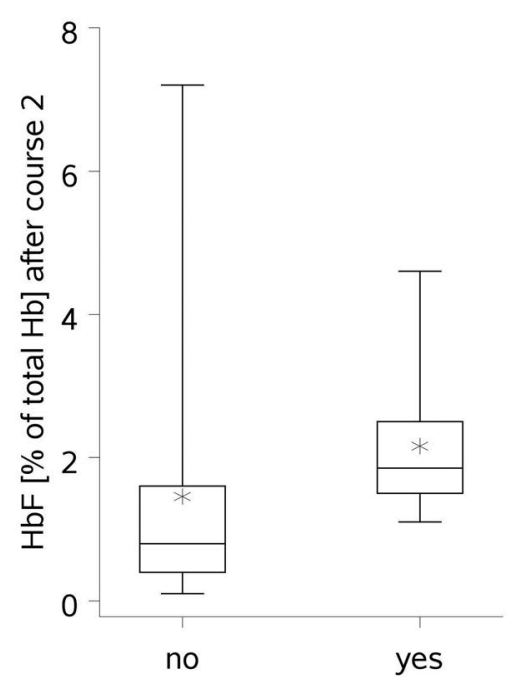

Remission status CR/PR

Figure 1. HbF kinetics in patients with myelodysplastic syndrome/acute myeloid leukemia during treatment with decitabine. (A) Box plot of $\mathrm{HbF}$ values prior to treatment with decitabine and after each of the first eight treatment courses in patients with myelodysplastic syndrome $(n=15)$ or acute myeloid leukemia $(n=25)$ for whom there was more than one measurement of $\mathrm{HbF}$ level. $\mathrm{HbF}$ was measured prior to treatment (= cycle 0 ) in 39 of these patients, after courses 1 to 8 (= cycles $1,2,3$, etc.) in $38,32,24,18,14,10,7$, and 9 of these patients, respectively. Outliers are plotted as individual points, extreme values as stars. For each of cycles 0,1 , and 3 , one extreme value is not displayed in the diagram, and one outlier is not shown for cycle 2. (B) Two representative vignettes of each of the four groups of $\mathrm{HbF}$ responses to decitabine treatment are shown: initially normal $\mathrm{HbF}$ induced to levels above (group A) or remaining within the normal range during treatment (group B); already elevated pre-treatment $\mathrm{HbF}$ remaining elevated (group $\mathrm{C}$ ) or decreasing to normal levels (group D). Shaded areas within the charts indicate values outside the normal range. The end of each decitabine treatment course is indicated with a numbered arrow. $\mathrm{Hb}$ : hemoglobin; HbF: fetal hemoglobin; PLT: platelets; WBC: white blood cells. (C) Box plot of HbF values at the end of the second course of decitabine treatment in 32 MDS/AML patients showing higher $\mathrm{HbF}$ levels in patients achieving complete or partial remission (CR, PR) as best overall response (right) compared to patients who did not attain CR/PR (left). 
A

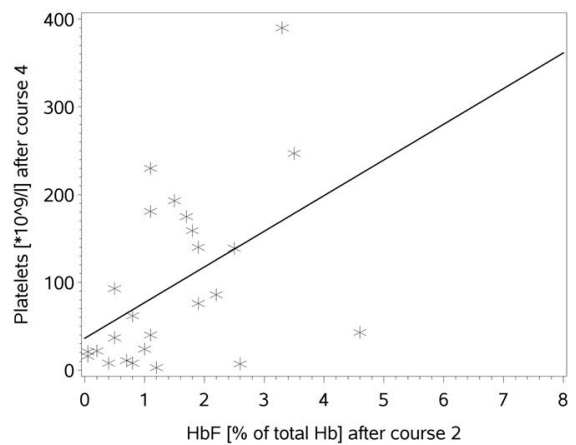

C

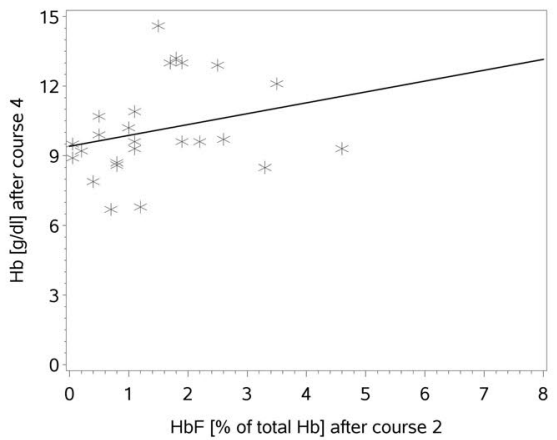

B

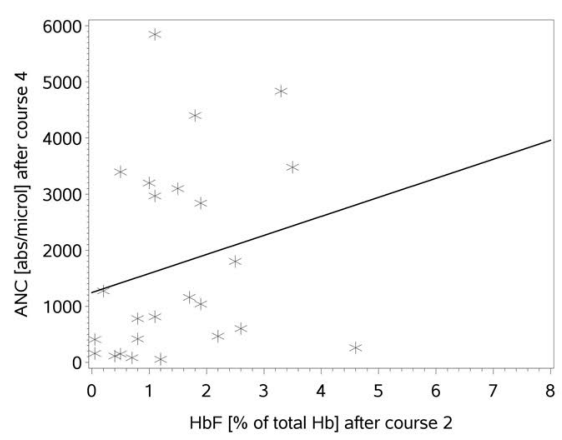

D

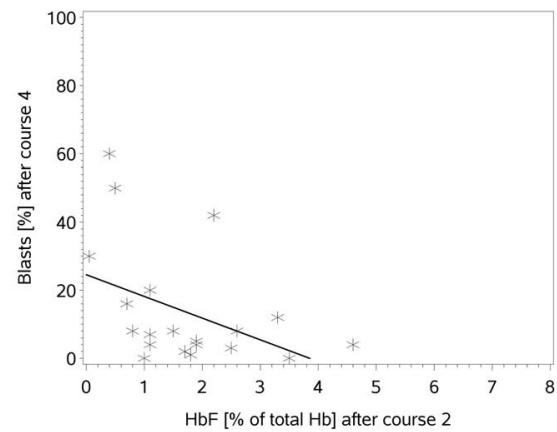

E

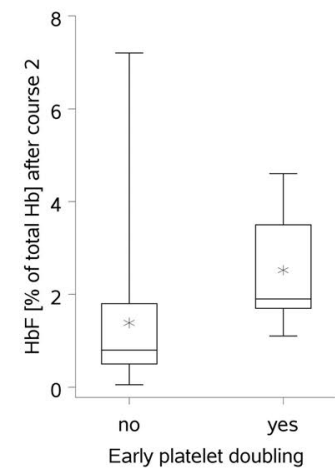

Figure 2. HbF levels after two courses of decitabine treatment are associated with responses of different hematologic lineages after course 4 , and with early platelet doubling. HbF values after treatment course 2 (x-axis) in patients with myelodysplastic syndrome (MDS)/acute myeloid leukemia (AML) who received at least two cycles of decitabine were plotted against (A) platelet counts $(n=25)(y$-axis), (B) absolute neutrophil counts $(n=25),(C)$ hemoglobin levels $(n=25)$, and (D) the percentage of bone marrow blasts $(n=21)$, as determined after course 4 . Linear regression equations are represented as lines and were estimated as $(A)$ platelets $=36+41 * \mathrm{HbF},(B)$ absolute neutrophil count $=1243+340 * \mathrm{HbF},(\mathrm{C})$ hemoglobin $=9.4+0.5 * \mathrm{HbF},(\mathrm{D})$ percentage bone marrow blasts $=25-6 * \mathrm{HbF}$. (E) Box plot demonstrating significantly higher $\mathrm{HbF}$ values after the second course of decitabine treatment in MDS/AML patients who achieved platelet doubling already after one course of decitabine.

undergone hematopoietic stem cell transplantation at the time of their transplant, this difference lost statistical significance $(P=0.098)$ (Online Supplementary Figure S6). The secondary endpoints, progression-free survival and AMLfree survival were also investigated and showed a trend to a more favorable outcome for patients with elevated $\mathrm{HbF}$ : the median progression-free survival was 7.7 months versus 2.4 months ( $\mathrm{HR}=0.32 ; 95 \%$ CI: $0.10-1.10 ; P=0.07$ ) (Figure $3 \mathrm{~B}$ ) and the median AML-free survival was 13.1 months versus 7.6 months ( $\mathrm{HR}=0.42$; $95 \%$ CI: 0.13-1.38; $P=0.15$ ) (Figure 3C).

In the AML cohort, 17 patients had HbF determinations available after two courses of treatment and could be included in a survival analysis. There was no significant difference in overall survival between those with elevated
$\mathrm{HbF}(\mathrm{n}=9)$ and those with normal $\mathrm{HbF}(\mathrm{n}=8)$ : the median overall survival was 17.3 and 11.6 months, respectively ( $\mathrm{HR}=0.68 ; 95 \%$ CI: 0.23-1.96; $P=0.47$ ) (Figure 3D).

\section{Elevated HbF levels are observed in decitabine-treated patients with myelodysplastic syndrome/acute myeloid leukemia with bone marrow blast} clearance, and decline at relapse

To investigate whether malignant cells or normal, emerging erythroid precursors synthesize the elevated $\mathrm{HbF}$ in response to HMAs, linear regression analyses were performed (Figure 4A). This showed an association between $\mathrm{HbF}$ induction after four treatment courses and a decreasing percentage of blasts at this time point in 17 MDS/AML patients. 
A

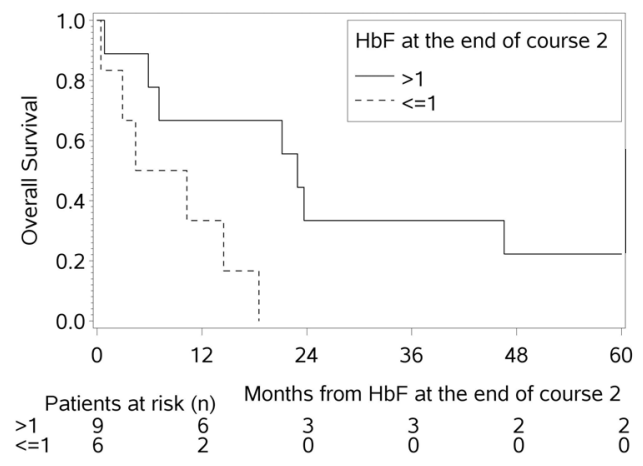

C

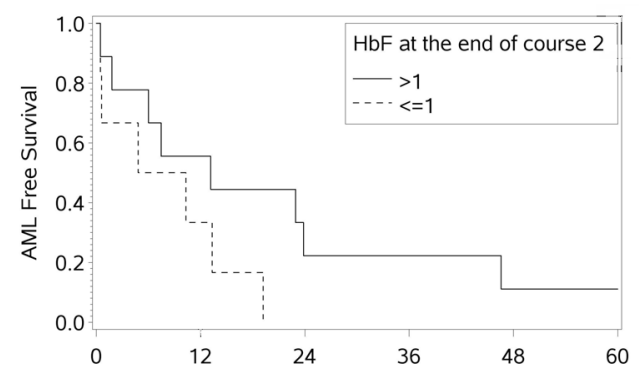

Patients at risk (n) Months from $\mathrm{HbF}$ at the end of course 2
B

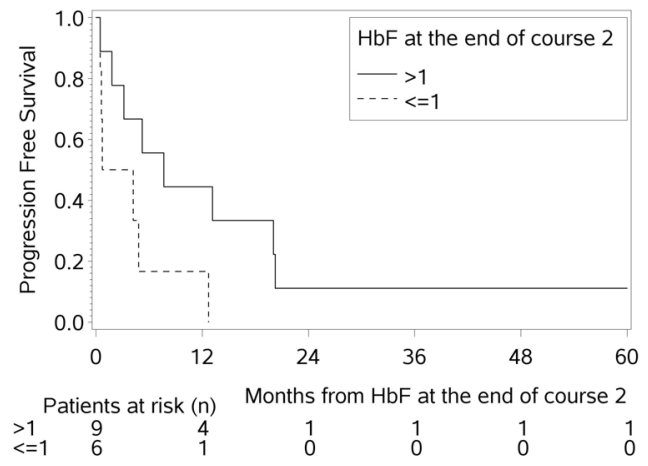

D

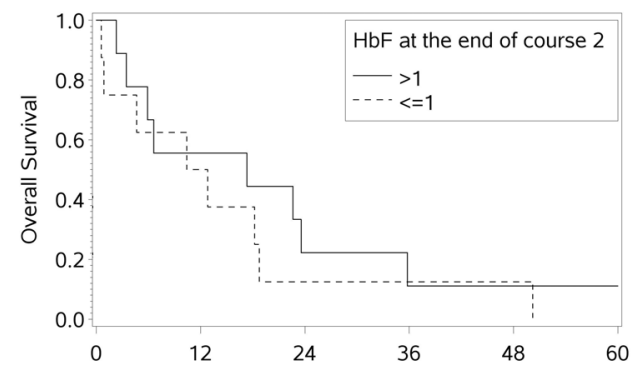

Patients at risk (n) Months from $\mathrm{HbF}$ at the end of course 2 $\begin{array}{lcccccc}>1 & 9 & 5 & 2 & 1 & 1 & 1 \\ <=1 & 8 & 4 & 1 & 1 & 1 & 0\end{array}$

Figure 3. Elevated $\mathrm{HbF}$ after course 2 of decitabine treatment is associated with improved survival in patients with myelodysplastic syndrome. Kaplan-Meier survival estimates were determined according to whether $\mathrm{HbF}$ after course 2 of decitabine treatment was in the normal range (i.e. 0-1.0\% of total hemoglobin) or elevated (i.e. >1.0\%). (A) Overall survival of 15 patients with myelodysplastic syndrome (MDS), two in the group with elevated $\mathrm{HbF}$ censored at 100 months (still alive in remission following allografting). (B) Progression-free survival of 15 MDS patients, one in the group with elevated $\mathrm{HbF}$ censored (still alive in remission following allografting). (C) Acute myeloid leukemia (AML)-free survival of 15 MDS patients, one in the group with elevated HbF censored (still alive in remission following allografting). (D) Overall survival of $17 \mathrm{AML}$ patients, one in the group with elevated HbF censored (still alive in remission following allografting).

Looking in more detail at the subgroup of 18 patients who received more than four courses of treatment, it was noted that six attained not only a multilineage hematologic response but also bone marrow blast clearance. Interestingly, in all of them $\mathrm{HbF}$ levels were, or became, elevated at the time of remission. In four of these patients, the complete remission status could be confirmed by cytogenetics: chromosomal abnormalities present at baseline were no longer detectable at that point (cytogenetic remission; in several of these patients, suppression of the abnormal clone was confirmed by fluorescence in situ hybridization).

Taken together, these analyses strongly suggested that $\mathrm{HbF}$ induction observed after four courses of treatment occurred preferentially in the emerging non-clonal erythroid cells, in which epigenetically silenced beta-globinlike genes were reactivated by treatment with the HMA.

For seven MDS/AML patients, $\mathrm{HbF}$ measurements were obtained both after the end of decitabine course 2 and at the time of hematologic relapse. Relative to an elevated $\mathrm{HbF}$ level after course 2 (median 1.9\%; range, 1.5-4.6\%), a decrease was observed in all seven patients at the time of relapse (median 1.1\%; range, $0.2-1.9 \%$ ). In two of these patients (both of whom had a complex karyotype), the decline in $\mathrm{HbF}$ level preceded the hematologic relapse, implicating it as a potential early predictor of relapse in a subgroup of patients. Notably, the initial increase after course 2 compared to pre-treatment $\mathrm{HbF}$ levels (available for 6 patients: median $1.2 \%$; range, $0.3-3.9 \%$ ) became reversed at relapse in five of the six patients (Figure 4B).

\section{Decitabine triggers an erythroid but not a megakaryocytic maturation program in bi-potential myeloid leukemia cells}

To model the effects of decitabine in vitro, two myeloblastic cell lines (K562, HEL) with bi-lineage differentiation potential were treated with decitabine at nontoxic concentrations. Striking morphological changes included polyploidy and cytoplasmic maturation indicative of partial erythroid differentiation (Figure $5 \mathrm{~A}$ ), confirmed by benzidine staining in K562 cells: decitabine- and hemin- but not PMA-treated cells became hemoglobinpositive (Figure 5B). K562 cells treated with PMA developed morphological changes indicative of megakaryocytic differentiation and induction of surface CD41/61 whereas lack of CD41 detection by FACS analysis after decitabine 
and hemin indicated absence of megakaryocytic differentiation (Figure 5C).

Transcriptome profiling by mRNA expression arrays in $\mathrm{K} 562$ cells revealed the greatest similarity between heminand decitabine-treated cells (Figure 6A,B). Notably, transcriptome changes of PMA-treated K562 cells were most extensive and clustered most distantly from those of all other treatments (Figure 6A,B). In HEL cells, variable probes also differed considerably between decitabine and PMA treatment (Online Supplementary Figures S8 and S9). Gene ontology analyses of upregulated transcripts consistently identified terms related to erythropoiesis and iron metabolism among the top regulated transcript groups in decitabine-treated cells whereas terms related to megakaryocyte lineage differentiation did not show significance (data not shown).

Among the transcripts upregulated by decitabine, almost all major globin genes could be identified (Figure 6C). Decitabine-treated K562 showed a >7-fold induction of alpha-1/alpha-2-globin transcription whereas PMA treatment did not alter alpha-globin transcription. Gamma-globin transcription was induced by all three treatments, with decitabine exhibiting the most pronounced effect. A strong induction was also noted for zeta-globin transcription upon decitabine and hemin, but not PMA, treatment. Similar patterns were noted for HEL (data not shown).

To prove induction of functionally competent $\mathrm{HbF}$ molecules in K562 cells by decitabine treatment, we quantified hemoglobin tetramers by cation-exchange chromatography. In two independent experiments, a reproducible timeand dose-dependent (albeit modest) induction of $\mathrm{HbF}$ tetramers was noted (Figure 6D).

\section{Decitabine-induced globin transcription in K562 cells is associated with GATA1 gene demethylation and upregulation}

To determine whether transcriptional upregulation of both the hemoglobin gamma 1 (HBG1) and 2 (HBG2) gene was a consequence of direct DNA methylation changes at the locus control region or at direct upstream regulatory regions of both genes, DNA methylation was assessed globally by methyl-CpG immunoprecipitation, as previously described. ${ }^{24}$ No enrichment could be demonstrated in untreated or in decitabine-treated K562 cells, indicating absence or only very low levels of DNA methylation at the $H B G 1$ and $H B G 2$ promoter and at the locus control region (Online Supplementary Figure S10). The gamma-globin locus is known to be devoid of a CpG island, ${ }^{25}$ and was shown to be unmethylated when selected $\mathrm{CpG}$ sites were interrogated for their methylation status by using methylation-sensitive restriction enzymes. ${ }^{26}$

The presence of activating H3K4me3 and H3K9ac histone marks (from K562 data sets of the ENCODE consortium $^{27}$ ) and absence of the repressive mark H3K27me3 (data not shown) indicated that transcriptional activity was already present in untreated cells at both loci, which could be demonstrated by the elevated $H B G 1 / H B G 2$ probe intensity in the mRNA expression array data (Figure 6C).

GATA1 has been identified as a key regulatory factor which binds prominently to the locus control region of the beta-globin locus (Online Supplementary Figure S10). In order to understand how HMA treatment might contribute to the transcriptional upregulation of $H B G 1$ and HBG2 without altering pre-existing low levels of local DNA methylation in K562 cells, we assessed DNA methy-
A

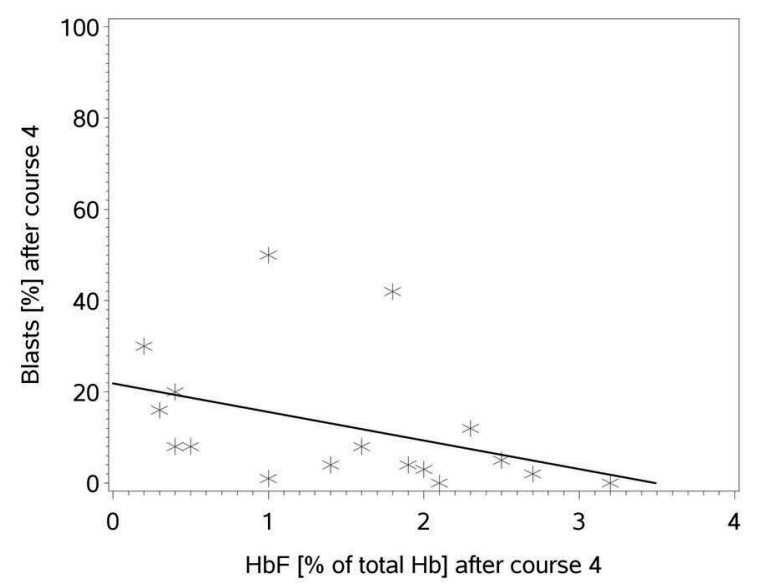

B

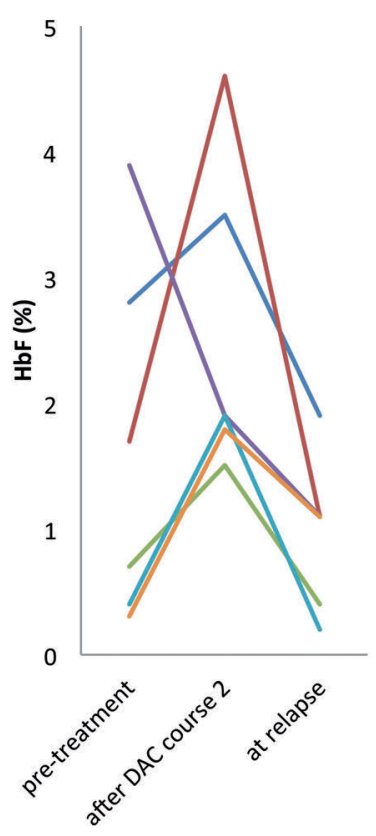

Figure 4. Induced HbF seems to be preferentially derived from non-malignant erythroid cells. (A) Linear regression model showing the association between $\mathrm{HbF}$ induction after four courses of treatment and a decreasing percentage of blasts at this time in 17 patients with myelodysplastic syndrome (MDS)/acute myeloid leukemia (AML). (B) Comparison of $\mathrm{HbF}$ levels prior to treatment, after course 2 of decitabine, and at relapse. Three MDS and three AML patients had $\mathrm{HbF}$ measurements available at all three time points. In five of the six patients, the initial increase in $\mathrm{HbF}$ after course 2 compared to pre-treatment levels became reversed at relapse. In four of these five patients, the level of $\mathrm{HbF}$ at relapse was even lower than that at the start of treatment.

lation at the GATA1 gene locus. Upon decitabine treatment, DNA methylation was substantially reduced in K562 cells at the GATA1 promoter region and at an upstream regulatory region (Figure 7A). Western blot analysis of K562 cells after 3 days of decitabine treatment demonstrated a dose-dependent, 2- to 3-fold upregulation of GATA1 protein at day 3 (Figure 7B). After 6 days of treatment, this effect was less pronounced. In contrast, PMA treatment strongly repressed GATA1 expression, an effect only modestly antagonized by decitabine.

\section{Discussion}

Clinically meaningful pharmacological induction of developmentally silenced $\mathrm{HbF}$ gene expression ${ }^{9,28}$ is a prime example of what has been termed epigenetic therapy. However, the broad clinical application of this approach in hemoglobinopathies has been limited by concerns of long-term mutagenic effects in these chronic disorders. The recent advent of DNA-hypomethylating treatment using azanucleoside DNA methyltransferase 
A

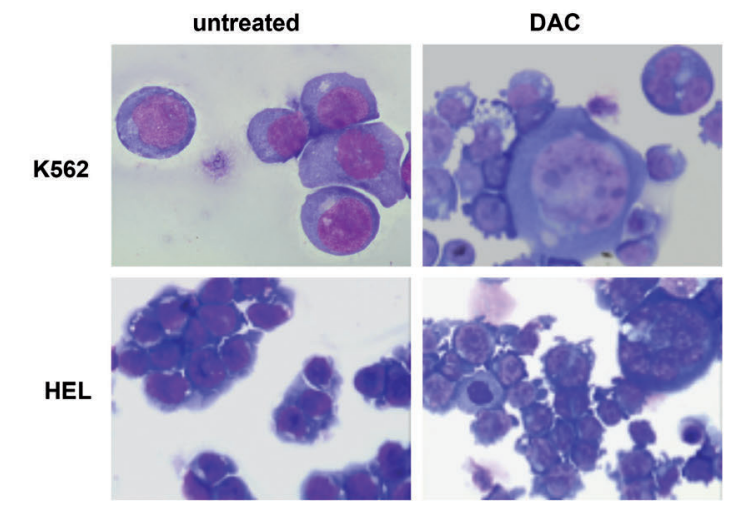

B

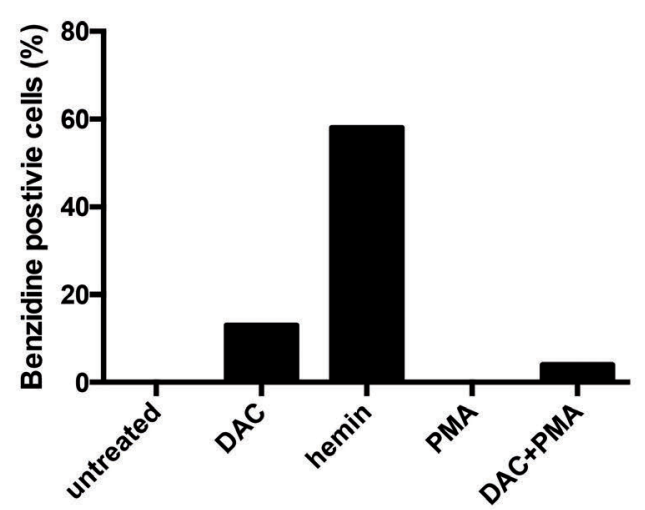

C

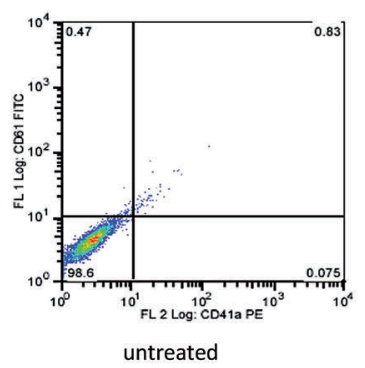

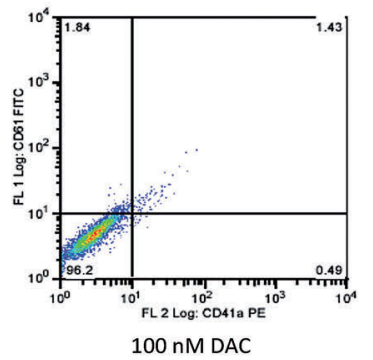

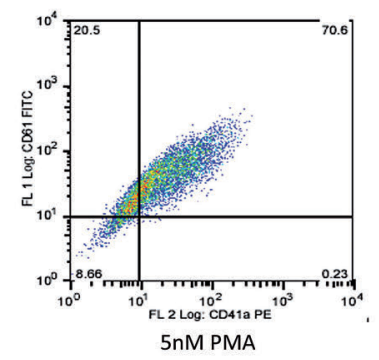

Figure 5. Decitabine induces erythroid differentiation and hemoglobin synthesis in K562 and HEL early myeloid progenitor cells. (A) K562 and HEL cells were treated with three $24 \mathrm{~h}$ pulses of $100 \mathrm{nM}$ decitabine. Morphological signs of erythroid differentiation upon decitabine (DAC) treatment were determined by cytospin preparation and May-Grünwald staining. (B) Hemoglobin synthesis in $\mathrm{K} 562$ cells was determined by benzidine staining. Cells were treated with DAC (three $24 \mathrm{~h}$ pulses, $100 \mathrm{nM}$ ), hemin ( $50 \mu \mathrm{M}$ for $48 \mathrm{~h}$ ), phorbol 12-myristate 13-acetate (PMA, $5 \mathrm{nM}$ ) and a combination of DAC and PMA at these concentrations. For each experimental point, 300 cells were counted, with blue cells being considered hemoglobin-positive. (C) Flow cytometry analysis of CD41/61 surface markers (highly specific for megakaryocytic differentiation) showed differentiation with PMA but not DAC treatment.

A
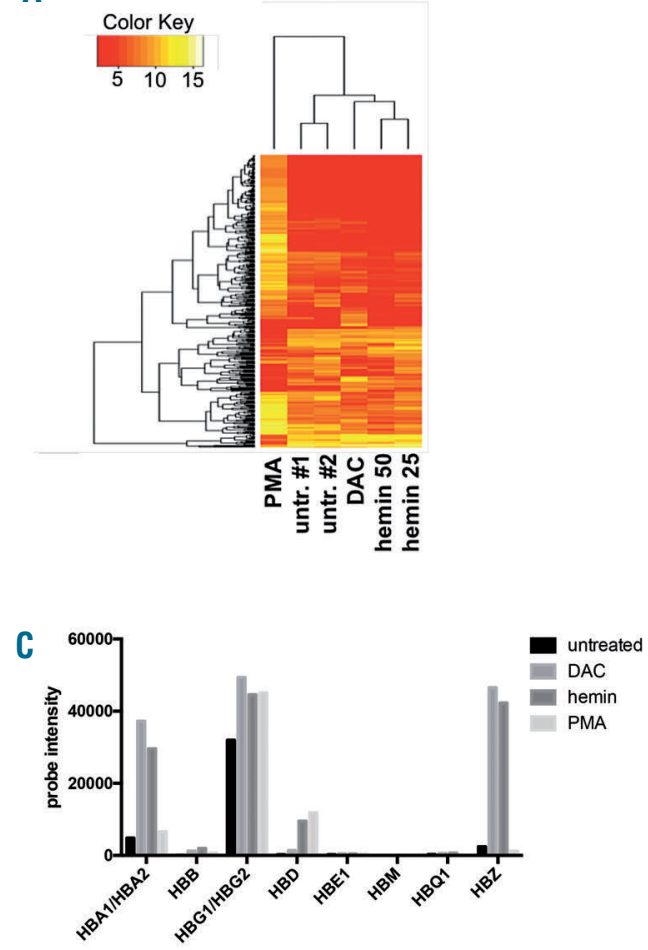

B

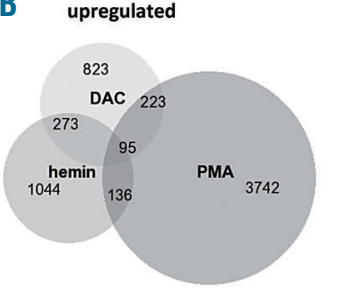

downregulated

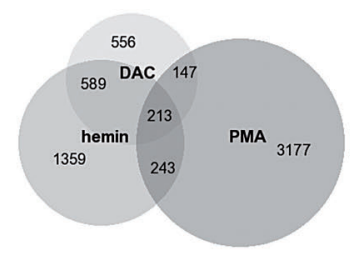

D

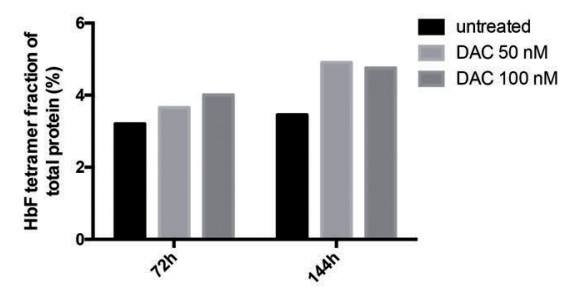

Figure 6. Decitabine treatment induces an erythroid transcriptome signature, globin chain expression and fetal hemoglobin assembly in K562 cells. (A) Transcriptome analyses were performed in K562 cells upon treatment (as described in the legend to Figure 5) with decitabine (DAC, $100 \mathrm{nM}$ ), hemin $(25$ and $50 \mu \mathrm{M})$, phorbol 12-myristate 13-acetate PMA (PMA, $5 \mathrm{nM}$ ) or without treatment (untreated \#1 - no treatment, untreated \#2 - phosphatebuffered saline as a vehicle control) using mRNA microarrays (HG-U133plus 2.0 gene chip, Affymetrix). The most variable probes (relative standard deviation among all samples $\geq 2$ ) are displayed as a heatmap with unsupervised hierarchical clustering (Euclidian distance). (B) Venn diagram displaying unique and shared $\geq 2$-fold upregulated and $\geq 2$-fold downregulated probes between the three treatments in K562 cells. (C) Relative mean probe intensities representing expression of globin chain transcripts: HBA1/HBA2, alphaglobin 1 and 2; HBB, beta-globin; HBG1/HBG2, gamma-globin 1 (Ggamma) and 2 (A-gamma); HBD, deltaglobin; HBE1, epsilon-globin 1; HBM, mu-globin; HBQ1, theta-globin, HBZ, zeta-globin) in untreated K562 cells and upon DAC, hemin and PMA treatment, respectively. (D) Increase of functional $\mathrm{HbF}$ tetramers determined by high-performance liquid chromatography as a fraction of total cellular protein upon DAC treatment (50 and $100 \mathrm{nM}$ ) after 72 and 144 h, respectively. Note the time-dependent incremental rise in $\mathrm{HbF}$ (dose-dependent at $72 \mathrm{~h}$ ). 


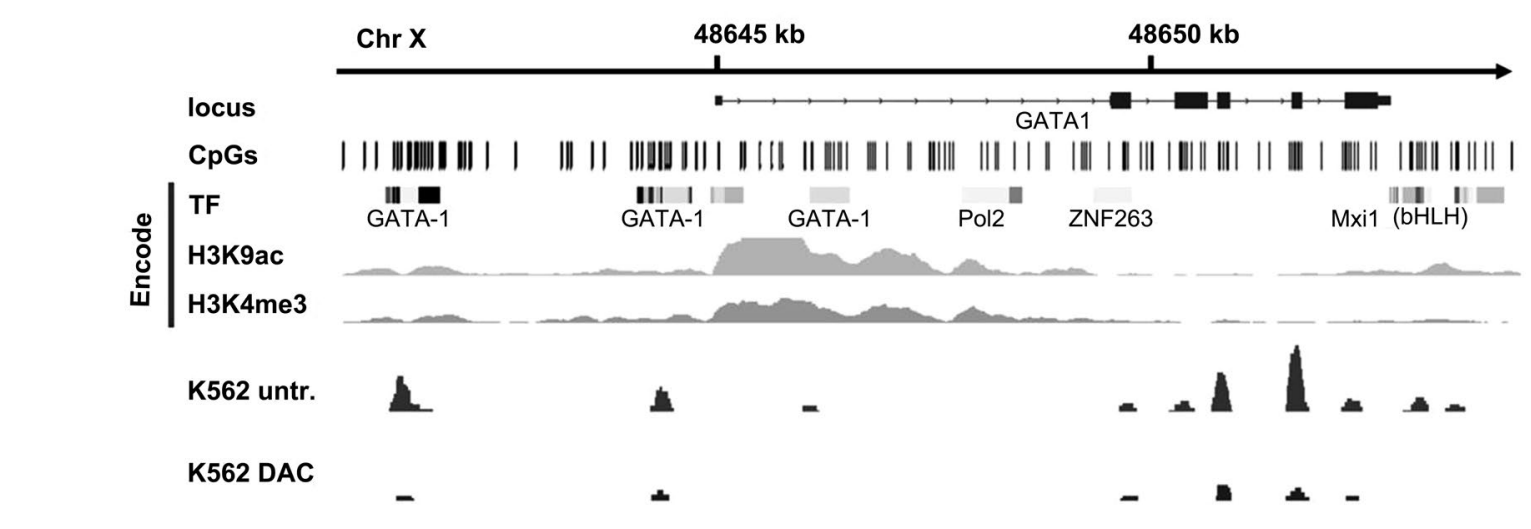

B

K562

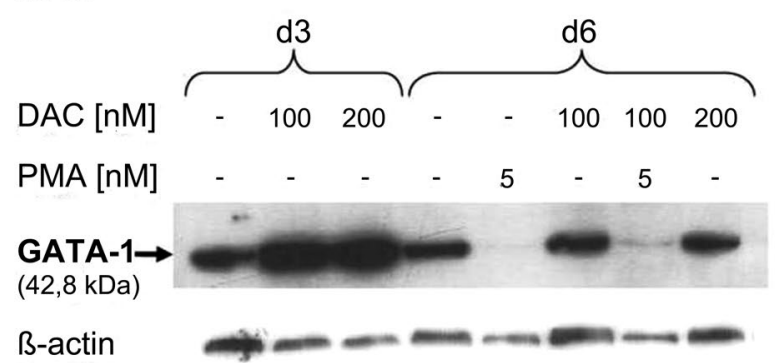

Figure 7. Decitabine induces gene demethylation and expression of the erythroid-specific transcription factor GATA1 in K562 cells. (A) Schematic representation of the GATA1 gene locus. The GATA1 gene is depicted as a black line from 5' (left) to 3' (right) with exons represented as boxes. CpG density (CpGs) is indicated by vertical bars. Transcription factor (TF) binding sites were determined through combined TF chromatin immunoprecipitation sequencing (ChIP-seq) experiments from different tissues/cell lines published by the ENCODE consortium. Likewise, activating histone marks H3K9ac and H3K4me3 are taken from ChIPseq experiments in untreated K562 cells which were published and made publicly available from the ENCODE consortium. DNA methylation was assessed by enrichment through methylCpG immunoprecipitation sequencing experiments in untreated K562 cells (K562 untr.) and in K562 cells treated with decitabine (K562 DAC). (B) K562 cells were treated with three $24 \mathrm{~h}$ pulses of $100 \mathrm{nM}$ or $200 \mathrm{nM}$ decitabine and harvested on days 3 and 6 . PMA 5 nM was added to the culture media for the final $48 \mathrm{~h}$. Immunoblotting of whole cell lysates with rat anti-GATA1. Immunoblotting with mouse anti-beta-actin was performed to control for lane loading.

inhibitors in MDS and AML has re-kindled an interest in $\mathrm{HbF}$ regulation in vivo. Specifically, we and others have recently described $\mathrm{HbF}$ induction in patients with $\mathrm{MDS}$ or AML receiving the DNA methyltransferase inhibitors azacitidine or decitabine. ${ }^{14-16,29}$

Since HMAs have to be administered over repeated treatment cycles in order to induce responses (which then occur only in about half of the patients), early markers predicting subsequent outcome are urgently needed in order to better advise patients whether to continue HMA treatment or switch to alternative therapy.

In order to investigate induction of $\mathrm{HbF}$ as a potential predictor of outcome, we chose the time point at the end of two courses of decitabine treatment, i.e. approximately 12 weeks after starting treatment, as the most meaningful: it disclosed the first robust $\mathrm{HbF}$ induction (Figure $1 \mathrm{~A}$ ), and was still early enough to be useful for predicting later outcome (whereas information at later time points would be a "self-fulfilling prophecy" regarding response and survival). Indeed, higher $\mathrm{HbF}$ at this time point was associated with overall objective responses and, particularly in MDS patients, with improvement of the different hematopoietic lineages after four courses of treatment. Notably, MDS patients with elevated $\mathrm{HbF}$ after two course of decitabine treatment had longer overall survival and trends to longer progression-free and AML-free survival. For AML patients, the median overall survival was also nominally longer in this group, but the difference was not statistically significant (possibly because at that time point, half of the AML patients had already died). Time point optimization in AML patients therefore appears necessary, particularly in view of the presently used decitabine treatment schedules of drug administration 5 or 10 days every 4 weeks. It was encouraging to note that higher $\mathrm{HbF}$ levels after two courses of treatment were associated with platelet doubling after one course, one of the few established early dynamic predictors of outcome with HMAs. ${ }^{30,31}$

In order to assess whether these results are applicable in clinical practice, and given the fact that a different decitabine dose is commonly used in MDS and AML patients at present, these results warrant validation in a larger cohort of patients treated with current dosing schemes. For this purpose, serial measurements of $\mathrm{HbF}$ have recently been performed in decitabine-treated AML patients randomized within the "inDACtion versus induction" Intergroup AML trial 1301 of the EORTC Leukemia Group (NCT02172872). 
With the perspective of exploiting $\mathrm{HbF}$ as a potential biomarker for response to HMA therapy, it might be used for selecting a cohort of MDS/AML patients who exhibit a significant increase in $\mathrm{HbF}$ after two cycles of decitabine treatment as candidates for a future clinical trial. Such a trial could have the objective to increase the effectiveness of HMA therapy by dose-schedule modifications and/or in combination with other epigenetic or other agents to increase the duration of response.

In practical terms, $\mathrm{HbF}$ measurement during $\mathrm{HMA}$ treatment needs to be compared in different laboratories (at this study's central laboratory, HPLC quantification of different rare $\mathrm{Hb}$ species, including $\mathrm{HbF}$, has been optimized for linear quantification also of smaller amounts). However, baseline $\mathrm{HbF}$ is also a promising predictor of HMA response and outcome, as recently demonstrated in the same cohorts of patients. ${ }^{16}$ At first sight it appears counter-intuitive that pre-treatment high expression may be biologically linked to outcome. However, as already discussed, ${ }^{16}$ elevated pre-treatment $\mathrm{HbF}$ levels may reflect incomplete silencing by methylation (and possibly other epigenetic mechanisms) of the gamma-globin locus, providing a potential surrogate marker for higher de novo sensitivity to HMAs. Interestingly, Cross et al. ${ }^{32}$ made a similar observation studying long interspersed element (LINE)-1 methylation in AML patients treated with azacitidine: lower LINE-1 methylation prior to treatment, but not early hypomethylation under treatment, predicted hematologic response to this in vivo hypomethylation.

What is the cellular source of $\mathrm{HbF}$ during the different treatment phases in MDS and AML patients receiving HMAs? In untreated MDS patients clonal erythroid progenitors, ${ }^{33}$ and in untreated AML patients residual normal, non-clonal erythroid progenitors may be the source of HbF-containing erythrocytes. ${ }^{34}$ In contrast, in patients attaining a complete or cytogenetic remission, it is more likely that the target cell of HMAs (presumably achieving hypomethylation and transcriptional de-repression of the beta-globin-like gene locus) is part of the non-clonal erythropoiesis, as in patients with solid tumors who show $\mathrm{HbF}$ induction during HMA treatment. ${ }^{10,11}$ The increase in platelet count after decitabine treatment indicates that decitabine reduced or eliminated the suppressive action of the malignant cells on normal hematopoiesis, with subsequent expansion of normal hematopoietic stem cells, which undergo differentiation. At the time of hematologic relapse, the decline in $\mathrm{HbF}$ levels might be due to the recurrence of the malignant clone. This contrasts with the model of increased $\mathrm{HbF}$ levels in juvenile myelomonocytic leukemia resulting from epigenetic dysregulation of beta-like-globin genes in leukemic cells. ${ }^{35}$ Serial immunohistochemical bone marrow studies for $\mathrm{HbF}$ expression in MDS/AML patients receiving HMAs are warranted to determine the cell of origin of $\mathrm{HbF}$ production during the different phases of treatment.

Modeling the effects of decitabine on the erythroid versus megakaryocytic lineage in two bi-potential myeloid cell lines, activation of an erythroid but not megakaryocytic gene expression program was observed, including induction of gamma-globin expression and induction, albeit modest, of $\mathrm{HbF}$ tetramer formation. We could demonstrate that decitabine treatment regulated many of the genes also regulated by hemin (including mRNA for erythroid-specific transcription factors and beta-like-globin genes), and induced GATA1 at the protein level, con- comitantly with demethylation at several cis-regulatory regions known to be important for the regulation of this gene. ${ }^{36,37}$ Notably, the overlap between the transcriptome changes induced by decitabine versus hemin was more marked in the downregulated genes compared to the upregulated ones. Despite demonstrating GATA1 gene demethylation following decitabine treatment, we are unable to conclude that GATA1 induction is a direct consequence of demethylation or is occurring during erythroid differentiation triggered via other factors. Here, a similar DNA methylation analysis of K562 cells treated with hemin instead of decitabine would address this "cause or consequence" question.

Taken together, the cell line experiments suggested that increased levels of $\mathrm{HbF}$ can also occur because of the effects of decitabine on malignant cells of the erythroid lineage. However, since a cell line is not a good model of the normal functional hematopoietic hierarchy, no conclusion can be drawn as to why erythroid rather than megakaryocytic differentiation was observed.

Is there a clinical relevance of induction of $\mathrm{HbF}$ beyond HMA treatment? Very recently, in a preclinical study a novel, specific inhibitor of histone deacetylase $1 / 2$ also demonstrated a strong propensity to induce $\mathrm{HbF}^{38}$ Furthermore, it is well established that inhibitors of the first histone lysine-specific demethylase (LSD)1, including novel, highly specific LSD1/KDM1A inhibitors such as $\mathrm{RN}-1$, are able to reactivate a silenced beta-globin-like gene locus. ${ }^{39}$ Furthermore, UNC0638, a selective inhibitor of the histone methyltransferases EHMT1 and EHM2, has the ability to induce $\mathrm{HbF}$ expression, and this potency is enhanced when the drug is combined with decitabine or the histone deacetylase inhibitor entinostat. ${ }^{40}$ Very recently, pomalidomide was also shown to be able to induce $\mathrm{HbF}$ in patients with multiple myeloma. ${ }^{41}$ Thus, serial $\mathrm{HbF}$ measurements in these different clinical settings may be interesting in order to determine whether the kinetics of this parameter is predictive of treatment response.

In conclusion, the technically simple test of assaying $\mathrm{HbF}$ levels warrants further prospective studies since the time to best response in patients treated with HMAs is often in the range of 4-6 months. Earlier tailoring of treatment is, therefore, highly desirable. It will be of interest to determine the predictive value of $\mathrm{HbF}$ levels compared to other, already established predictors of HMA response such as hematologic parameters, genetic and DNA methylation markers.

\section{Acknowledgments}

The authors wish to thank Tobias Berg, Dietmar Pfeifer, Heike Pahl, Claudia Schmoor, Roland Schüle, Christian Flotho and others who kindly provided helpful input and critical discussion during the course of this study. We really appreciate the experimental contributions of Lena Pados (nee Kasten), and the efforts of Thomas Epting (hemoglobin quantification) and Ljudmila Bogatyreva (statistics).

\section{Funding}

This work was supported by the DFG, SFB 992 (MEDEP, project C04). Further research funding: DFG-SPP 1463 (ML, CP), DFG-FOR 2674 (A01: CP; A05: ML/HB; A09: $C P / M L)$, Wilhelm-Sander-Stiftung (grant 1999.032.2), German Cancer Aid (DKH 111210: HB; Max Eder stipend DKH 110461: RC). 


\section{References}

1. Daskalakis M, Nguyen TT, Nguyen C, et al. Demethylation of a hypermethylated $\mathrm{P} 15 / \mathrm{INK} 4 \mathrm{~B}$ gene in patients with myelodysplastic syndrome by 5 -aza-2'-deoxycytidine (decitabine) treatment. Blood. 2002;100(8): 2957-2964.

2. Tsai HC, Li H, Van Neste L, et al. Transient low doses of DNA-demethylating agents exert durable antitumor effects on hematological and epithelial tumor cells. Cancer Cell. 2012;21(3):430-446

3. Klco JM, Spencer DH, Lamprecht TL, et al. Genomic impact of transient low-dose decitabine treatment on primary AML cells. Blood. 2013;121(9):1633-1643.

4. Claus R, Pfeifer D, Almstedt $M$, et al. Decitabine induces very early in vivo DNA methylation changes in blasts from patients with acute myeloid leukemia. Leuk Res. 2013;37(2):190-196

5. Chiappinelli KB, Strissel PL, Desrichard A, et al. Inhibiting DNA methylation causes an interferon response in cancer via dsRNA including endogenous retroviruses. Cell. 2015;162(5):974-986.

6. Roulois D, Loo Yau H, Singhania R, et al. DNA-demethylating agents target colorectal cancer cells by inducing viral mimicry by endogenous transcripts. Cell. 2015;162(5): 961-973.

7. Yang X, Han H, De Carvalho DD, Lay FD, Jones PA, Liang G. Gene body methylation can alter gene expression and is a therapeutic target in cancer. Cancer Cell. 2014;26(4):577-590.

8. Lübbert $M$, Daskalakis $M$, Kunzmann $R$, Engelhardt M, Guo Y, Wijermans P. Nonclonal neutrophil responses after successful treatment of myelodysplasia with low-dose 5-aza-2'-deoxycytidine (decitabine). Leuk Res. 2004;28(12):12671271.

9. Ley TJ, DeSimone J, Anagnou NP, et al. 5azacytidine selectively increases gammaglobin synthesis in a patient with beta+ thalassemia. N Engl J Med. 1982;307(24):14691475.

10. Chu BF, Karpenko MJ, Liu Z, et al. Phase I study of 5-aza-2'-deoxycytidine in combination with valproic acid in non-small-cell lung cancer. Cancer Chemother Pharmacol. 2013;71(1):115-121.

11. Gollob JA, Sciambi CJ, Peterson BL, et al Phase I trial of sequential low-dose 5-aza-2'deoxycytidine plus high-dose intravenous bolus interleukin-2 in patients with melanoma or renal cell carcinoma. Clin Cancer Res. 2006;12(15):4619-4627.

12. Koshy M, Dorn L, Bressler L, et al. 2-deoxy 5 -azacytidine and fetal hemoglobin induction in sickle cell anemia. Blood. 2000;96 (7):2379-2384

13. Olivieri NF, Saunthararajah Y, Thayalasuthan $\mathrm{V}$, et al. A pilot study of subcutaneous decitabine in beta-thalassemia intermedia. Blood. 2011;118(10):2708-2711.

14. Tan P, Wei A, Mithraprabhu S, et al. Dual epigenetic targeting with panobinostat and azacitidine in acute myeloid leukemia and high-risk myelodysplastic syndrome. Blood Cancer J. 2014;4:e170.

15. Gore SD, Baylin S, Sugar E, et al. Combined DNA methyltransferase and histone deacetylase inhibition in the treatment of myeloid neoplasms. Cancer Res. 2006;66(12):6361-6369.

16. Lübbert M, Ihorst G, Sander PN, et al. Elevated fetal haemoglobin is a predictor of better outcome in MDS/AML patients receiving 5-aza-2'-deoxycytidine (decitabine). Br J Haematol. 2017;176(4): 609-617.

17. Bissé E, Wieland H. High-performance liquid chromatographic separation of human haemoglobins. Simultaneous quantitation of foetal and glycated haemoglobins. J Chromatogr. 1988;434(1):95-110.

18. Belsley DA KE, Welsh RE. Regression Diagnostics. New York: John Wiley \& Sons, 1980.

19. Anderson JR, Cain KC, Gelber RD. Analysis of survival by tumor response and other comparisons of time-to-event by outcome variables. J Clin Oncol. 2008;26(24):39133915.

20. Claus R, Fliegauf M, Stock M, Duque JA, Kolanczyk M, Lübbert M. Inhibitors of DNA methylation and histone deacetylation independently relieve AML1/ETO-mediated lysozyme repression. J Leukoc Biol. 2006;80 (б):1462-1472

21. Miller CW, Young K, Dumenil D, Alter BP, Schofield JM, Bank A. Specific globin mRNAs in human erythroleukemia (K562) cells. Blood. 1984;63(1):195-200.

22. Rutherford T, Clegg JB, Higgs DR, Jones RW, Thompson J, Weatherall DJ. Embryonic erythroid differentiation in the human leukemic cell line K562. Proc Natl Acad Sci USA. 1981;78(1):348-352.

23. Guilbert LJ, Nelson DJ, Hamilton JA, Williams N. The nature of 12-O-tetradecanoylphorbol-13-acetate (TPA)-stimulated hemopoiesis, colony stimulating factor (CSF) requirement for colony formation, and the effect of TPA on [125I]CSF-1 binding to macrophages. J Cell Physiol. 1983;115(3): 276-282

24. Baer C, Claus R, Frenzel LP, et al. Extensive promoter DNA hypermethylation and hypomethylation is associated with aberrant microRNA expression in chronic lymphocytic leukemia. Cancer Res. 2012;72(15):3775-3785

25. Bird AP. CpG-rich islands and the function of DNA methylation. Nature. 1986;321 (6067):209-213

26. van der Ploeg LH, Flavell RA. DNA methylation in the human gamma delta beta-globin locus in erythroid and nonerythroid tissues. Cell. 1980;19(4):947-958.

27. An integrated encyclopedia of DNA elements in the human genome. Nature. 2012;489(7414):57-74

28. Saunthararajah Y. LD, DeSimone J. Epigenetic regulation of globin genes and disturbances in hemoglobinopathies. In: Lübbert M., Jones PA, ed. Epigenetic Therapy of Cancer. Berlin, Heidelberg: Springer, 2014

29. Press KR, Uy N, Keefer J, et al. Clinical eval- uation of combined azacitidine and entinostat on the induction of fetal hemoglobin in patients with acute myeloid leukemias and myelodysplastic syndromes. Leuk Lymphoma. 2017:2018;59(3):755-757.

30. van den Bosch J, Lübbert M, Verhoef G, Wijermans PW. The effects of 5-aza-2'deoxycytidine (decitabine) on the platelet count in patients with intermediate and high-risk myelodysplastic syndromes. Leuk Res. 2004;28(8):785-790.

31. van der Helm LH, Alhan C, Wijermans PW, et al. Platelet doubling after the first azacitidine cycle is a promising predictor for response in myelodysplastic syndromes (MDS), chronic myelomonocytic leukaemia (CMML) and acute myeloid leukaemia (AML) patients in the Dutch azacitidine compassionate named patient programme. Br J Haematol. 2011;155(5):599-606.

32. Cross M, Bach E, Tran T, et al. Pretreatment long interspersed element (LINE)-1 methylation levels, not early hypomethylation under treatment, predict hematological response to azacitidine in elderly patients with acute myeloid leukemia. Onco Targets Ther. 2013;6:741-748.

33. Choi JW, Kim Y, Fujino $M$, Ito $M$. Significance of fetal hemoglobin-containing erythroblasts (F blasts) and the F blast/F cell ratio in myelodysplastic syndromes. Leukemia. 2002;16(8):1478-1483.

34. Rautonen J, Siimes MA. Initial blood fetal hemoglobin concentration is elevated and is associated with prognosis in children with acute lymphoid or myeloid leukemia. Blut. 1990;61(1):17-20.

35. Fluhr S, Krombholz CF, Meier A, et al. Epigenetic dysregulation of the erythropoietic transcription factor KLF1 and the betalike globin locus in juvenile myelomonocytic leukemia. Epigenetics. 2017;12(8):715-723.

36. Takai J, Moriguchi T, Suzuki M, Yu L, Ohneda K, Yamamoto M. The Gata1 5' region harbors distinct cis-regulatory modules that direct gene activation in erythroid cells and gene inactivation in HSCs. Blood. 2013;122(20):3450-3460.

37. Moriguchi T, Suzuki M, Yu L, Takai J, Ohneda K, Yamamoto M. Progenitor stagespecific activity of a cis-acting double GATA motif for Gata1 gene expression. Mol Cell Biol. 2015;35(5):805-815.

38. Shearstone JR, Golonzhka O, Chonkar A, et al. Chemical inhibition of histone deacetylases 1 and 2 induces fetal hemoglobin through activation of GATA2. PLoS One. 2016;11(4):e0153767.

39. Rivers A, Vaitkus K, Ibanez V, et al. The LSD1 inhibitor RN-1 recapitulates the fetal pattern of hemoglobin synthesis in baboons (P. anubis). Haematologica. 2016;101(6):688697.

40. Renneville A, Van Galen P, Canver MC, et al EHMT1 and EHMT2 inhibition induces fetal hemoglobin expression. Blood. 2015;126(16):1930-1939.

41. Dulmovits BM, Appiah-Kubi AO, Papoin J, et al. Pomalidomide reverses gamma-globin silencing through the transcriptional reprogramming of adult hematopoietic progenitors. Blood. 2016;127(11):1481-1492. 